\title{
ANALISIS PERKIRAAN KEBUTUHAN DAN TARIF AIR BERSIH UNTUK PELABUHAN PERIKANAN SAMUDERA(PPS) LAMPULO KOTA BANDA ACEH
}

\author{
Putri Phara Intan ${ }^{\mathbf{1}}$, Azmeri $^{2}$, Eldina $^{3}$ \\ ${ }^{I}$ Magister Teknik Sipil Fakultas Teknik Universitas Syiah Kuala \\ ${ }^{2,3}$ Jurusan Teknik Sipil Fakultas Teknik Universitas Syiah Kuala \\ Jl. Syekh Abdurrauf No. 7, Kopelma Darussalam, Banda Aceh, 23111 \\ email: putripharaintan@ymail.com ${ }^{1}$,azmeri@unsyiah.ac.id ${ }^{2}$, \\ eldinafatimah28@gmail.com ${ }^{3}$
}

DOI: http://dx.doi.org/10.29103/tj.v10i2.338

(Received: July 2020 / Revised: August 2020 / Accepted: August 2020)

\begin{abstract}
Abstrak
Penelitian ini dilakukan Oktober-Desember 2019 di Pelabuhan Perikanan Lampulo, kecamatan Kuta Alam, kota Banda Aceh, Provinsi Aceh, bertujuan untuk mengetahui tingkat kebutuhan air bersih, jumlah tarif air bersih dan strategi pelayanan air bersih, dibatasi pada 3 unit kegiatan yaitu unit penangkapan, perkantoran dan pabrik es, menggunakan metode studi kasus dan analisis deskriptif kuantitatif. Dari hasil penelitian diketahui perkiraan kebutuhan air bersih pada unit penangkapan perhari/trip secara aktual sebesar 500-1.000 liter/trip untuk jenis kapal One Day Fishing 1-2 hari perjalanan, namun secara teoritis untuk jenis kapal ini membutuhkan 1.125 liter/trip dengan perhitungan konsumsi ABK 50 liter/orang/trip. Kebutuhan air bersih untuk semua jenis kapal dalam rangkaian aktifitas penangkapan ikan sebesar 117.900 liter/trip dalam kurun waktu sebulan aktifitas melaut dilakukan sebanyak 3 kali perjalanan dikarenakan untuk kapal>6 GT menempuh perjalanan 6-10 hari perjalanan. Saat ini untuk unit kegiatan perkantoran dan pabrik es adanya sumur bor yang dapat membantu aktifitas perhari, namun unit perkantoran di lingkungan PPS Lampulo membutuhkan air bersih sebesar 460 liter/hari dengan perhitungan konsumsi penggunaan air sebanyak 30 liter/orang/hari. Untuk unit kegiatan pabrik es membutuhkan air bersih dalam proses pembuatan Es Balok sebesar 115.500 liter/hari. Dalam penelitian ini dapat diketahui tarif air bersih yang memadai untuk memenuhi kebutuhan pelaku PPS Lampulo dengan harga Rp. $4.200 / \mathrm{m}^{3}$ namun harga tersebut memiliki kenaikan di tahun terakhir ini sesuai dengan kebijakan Peraturan Walikota Banda Aceh Nomor 15 Tahun 2017 tentang Penyesuaian Kelompok Pelanggan dan Tarif Air Minum. Dengan adanya Analisis SWOT diperoleh strategi peningkatan pelayanan dan peningkatan sarana serta prasarana di Pelabuhan Perikanan Samudera Lampulo, sehingga akan menimbulkan mobilisasi nelayan yang melakukan aktivitas bongkar muat.
\end{abstract}

Kata kunci: PPS Lampulo, Pelayanan, Kebutuhan Air Bersih, Tarif Air Bersih, Analisis SWOT.

\begin{abstract}
This research was conducted in October- December 2019 at the Lampulo Fishery Port, Kuta Alam District, Banda Aceh City, Aceh Province, the aims to determine the level of clean water needs, the amount of clean water rates and clean water service strategies in Lampulo PP, limited to 3 activity units namely the fishing unit, offices
\end{abstract}


and ice factories. This research uses the case study method and quantitative descriptive analysis. From the results of the study can be known estimated clean water needs in the capture unit per day / trip actually requires 500-1,000 liters / trip for the type of One Day Fishing ship 1-2 days trip. However, theoretically for this type of ship requires 1,125 liters / trip with the calculation of ABK consumption of 50 liters / person / trip. Clean water needs for all types of vessels in a series of fishing activities amounted to 117,900 liters / trip within a period of one month to sea activities carried out as many as 3 trips due to ships> 6 GT traveling 6-10 day trips. At present for the Office and Ice Factory activity units there are boreholes that can help with daily activities, however the Office Unit in the Lampulo PPS environment requires clean water of 460 liters / day with the calculation of consumption water usage of 30 liters / person / day. Whereas the Ice Factory activity unit requires clean water in the process of making Beams of Ice at 115,500 liters / day. In this research, it can be known that the Clean Water Tariff is adequate to meet the needs of Lampulo PPS actors at a price of Rp. 4,200 but the price has increased this past year in accordance with the policies of the Banda Aceh Mayor Regulation No. 15 of 2017 concerning Adjustment of Customers Groups and Drinking Water Rates. With the SWOT Analysis, it is obtained a strategy of service improvement and improvement of facilities and infrastructure at Lampulo Ocean Fisheries Port, so as it will lead to mobilization of fishermen who carry out loading and unloading activities.

Keywords: Lampulo PPS, Services, Clean Water Needs, Clean Water Rates, SWOT Analysis.

\section{Latar Belakang}

Pelabuhan perikanan merupakan suatu wilayah perpaduan antara wilayah daratan dan lautan yang dipergunakan sebagai pangkalan kegiatan dan penangkapan ikan yang dilengkapi dengan berbagai fasilitas sejak ikan didaratkan sampai ikan didistribusikan (Lubis, 2002), hal ini tentunya sesuai dengan penjelasan dalam pasal 18 UU No 9 tahun 1985 tentang perikanan bahwa pelabuhan perikanan sebagai suatu lingkungan kerja berfungsi sebagai; 1) pusat pengembangan masyarakat nelayan; 2) tempat berlabuh kapal perikanan; 3) tempat pendaratan hasil tangkapan; 4) tempat untuk memperlancar kegiatan kapal-kapal perikanan; 5) pusat pemasaran dan industri hasil tangkapan; dan 6) pusat pelaksanaan penyuluhan dan pengumpulan data perikanan. Pelabuhan perikanan sebagai suatu lingkungan kerja maka pembangunan pelabuhan perikanan harus memiliki tujuan tertentu. Tujuan ini tercapai apabila ditunjang dengan berbagai prasarana fasilitas seperti; fasilitas pokok, fasilitas fungsional, dan fasilitas tambahan.

Menurut (Lubis, 2000) pembangunan pelabuhan perikanan bertujuan untuk menunjang kegiatan produksi nelayan, agar kegiatan penangkapan, pemasaran, maupun pengolahannya menjadi optimal. Selanjutnya dinyatakan bahwa dalam usaha menunjang peningkatan produksi perikanan laut, maka tersedianya prasarana pelabuhan perikanan mempunyai arti yang sangat penting. Pelabuhan perikanan merupakan pusat pengembangan ekonomi perikanan ditinjau dari aspek produksi, pengolahan, dan pemasaran baik berskala lokal, nasional maupun internasional. Fungsi pelabuhan perikanan menyangkut berbagai aspek. Fungsi utama dari pelabuhan perikanan yaitu sebagai lingkungan kerja yang melaksanakan pelayanan umum (Guswanto, 2012). Oleh karena itu diperlukan adanya pengaturan secara lengkap mengenai organisasi Pelabuhan Perikanan.

Analisis Perkiraan Kebutuhan Dan Tarif Air Bersih Untuk Pelabuhan Perikanan Samudera(PPS) Lampulo Kota Banda Aceh - Putri Phara Intan, Azmeri, Eldina 
Pelabuhan perikanan merupakan basis utama dalam kegiatan industri perikanan tangkap yang harus dapat menjamin suksesnya aktivitas usaha perikanan tangkap di laut. Pelabuhan perikanan berperan sebagai terminal yang menghubungkan kegiatan usaha di laut dan di darat ke dalam suatu sistem usaha dan berdayaguna tinggi. Aktivitas unit penangkapan ikan di laut harus keberangkatannya dari pelabuhan dengan bahan bakar, makanan, es, dan lain-lain secukupnya. Informasi tentang data harga dan kebutuhan ikan di pelabuhan perlu dikomunikasikan dengan cepat dari pelabuhan ke kapal di laut. Setelah selesai melakukan pekerjaan di laut kapal akan kembali dan masuk ke pelabuhan untuk membongkar dan menjual ikan hasil tangkapan (Bambang, 2003).

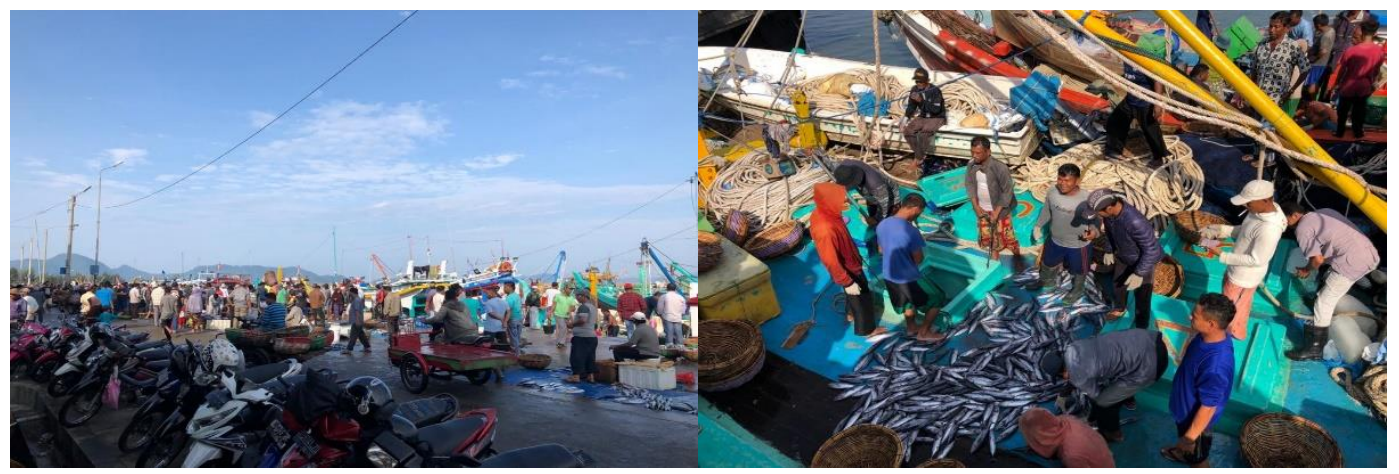

(a)

(b)

Gambar 1 (a) Kondisi Dermaga, (b) Bongkar muat hasil tangkapan

Kawasan Industri Perikanan Pelabuhan Perikanan Samudera (PPS) di desa Lampulo, kecamatan Kuta Alam, kota Banda Aceh mengalami permasalahan suplai air bersih yang belum lancer, sehingga sejumlah investor yang beroperasi di kawasan itu mengeluhkan tentang hal tersebut. Jaringan pipa PDAM Tirta Daroy kota Banda Aceh sudah pernah terpasang untuk mendukung kegiatan Peringatan Hari Nusantara Nasional pada bulan November Tahun 2015 yang lalu. Jaringan pipa PDAM Tirta Daroy yang terpasang tersebut mengaliri air dari sumber Krueng Aceh untuk dapat melayani kebutuhan PPS Lampulo. Untuk memenuhi kebutuhan pabrik es dan cold storage yang tersedia membutuhkan air bersih 60.000 s.d 70.000 liter/hari, namun fakta yang terjadi sekarang, kegiatan industri perikanan di PPS Lampulo tidak dapat didukung lagi oleh jaringan perpipaan yang ada, hal ini mengharuskan para investor atau pelaku industri perikanan membeli air bersih dari PDAM menggunakan mobil tangki.

Peraturan Menteri Kesehatan RI Nomor: 41 6/Menkes/Per/IX/1990 tentang syarat-syarat pengawasan kualitas air, air bersih adalah air yang digunakan untuk keperluan sehari-hari yang kualitasnya memenuhi syarat-syarat kesehatan dan dapat diminum apabila telah dimasak. Menurut Manual Teknis Upaya Penyehatan Air, Ditjen P2PLP Depkes RI (1996), kebutuhan air bersih masyarakat perkotaan berkisar 120 lt/org/hr, dan untuk masyarakat pedesaan 80 lt/org/hr. Air tersebut digunakan untuk keperluan sehari-hari dan keperluan pendukung lainnya termasuk yang mendukung kebutuhan-kebutuhan sekunder, sementara yang dimaksud air pada uraian ini, merupakan semua air yang terdapat di atas maupun di bawah permukaan tanah, termasuk dalam pengertian ini air permukaan, air

Analisis Perkiraan Kebutuhan Dan Tarif Air Bersih Untuk Pelabuhan Perikanan Samudera(PPS) Lampulo Kota Banda Aceh - Putri Phara Intan, Azmeri, Eldina 
tanah, air hujan, dan air laut yang berada di darat. Air bersih adalah air sehat yang dipergunakan untuk kegiatan manusia dan harus bebas dari kuman-kuman penyebab penyakit, bebas dari bahan-bahan kimia yang dapat mencemari air bersih tersebut. Air merupakan zat yang mutlak bagi setiap mahluk hidup, kebersihan air syarat utama bagi terjaminnya kesehatan (Dwijosaputro, 1981).

Peranan sektor swasta sangat penting dalam pola kepemerintahan dan pembangunan, karena peranya sebagai sumber peluang untuk meningkatkan produktivitas, penyerapan tenaga kerja, sumber penerimaan, investasi publik, pengembangan usaha, dan pertumbuhan ekonomi (Rahmawati, 2014).

\section{Metode Penelitian}

Penentuan lokasi ditentukan secara purposive atau sengaja dengan pertimbangan bahwasanya PPS Lampulo salah satu pelabuhan perikanan terbesar di Aceh yang membutuhkan perkiraan kebutuhan air bersih untuk dimanfaatkan. Sumber data yang diperlukan dalam penelitian seperti data primer dan data sekunder. Analisis data dilaksanakan dengan melakukan perhitungan metode deskriptif kuantitatif untuk menghitung jumlah pemakai air bersih, jumlah kebutuhan perharinya serta melakukan analisis perkiraan tarif air bersih yang layak hingga berpihak pada pelaku ekonomi lemah maupun berpendapatan tinggi. Armada perikanan yang terdapat di PPS Lampulo adalah jenis kapal motor yang dapat menjangkau daerah penangkapan yang lebih jauh dibandingkan perahu motor tempel dan perahu tanpa motor. Ukuran kapal tersebut sangat bervariasi, selain tujuan penggunaannya tidak selalu untuk menangkap ikan. Perkembangan armada perikanan tangkap berdasarkan ukuran kapal (Gross Tonage, GT) yang terdapat di PPS Lampulo, seperti pada tabel 1.

Tabel 1 Frekuensi jumlah kapal masuk berdasarkan ukuran kapal

\begin{tabular}{|c|c|c|c|c|c|c|c|c|}
\hline \multirow{2}{*}{ Tahun } & \multicolumn{7}{|c|}{ Gross Tonage Kapal (GT) } & \multirow{2}{*}{ Jumlah } \\
\hline & $<5$ & 6-10 & $11-20$ & $21-30$ & $31-50$ & $51-100$ & $>100$ & \\
\hline 2014 & 36 & 125 & 36 & 55 & 61 & 29 & 1 & 343 \\
\hline 2015 & 39 & 125 & 37 & 54 & 64 & 32 & 3 & 354 \\
\hline 2016 & 29 & 136 & 28 & 54 & 66 & 42 & 5 & 360 \\
\hline 2017 & 32 & 136 & 28 & 57 & 66 & 44 & 5 & 368 \\
\hline 2018 & 32 & 138 & 28 & 57 & 66 & 44 & 5 & 370 \\
\hline
\end{tabular}

\subsection{Tingkat Kebutuhan Air Bersih}

Tingkat kebutuhan air bersih di pelabuhan perikanan dihitung secara rinci dengan menggunakan formula (Pane, 2011):

$$
K A P P=(K A M+K A E+K A B
$$

di mana:

KAPP : Kebutuhan air di pelabuhan perikanan (liter/hari);

KAM : Kebutuhan air bersih untuk melaut (liter/hari);

KAE : Kebutuhan air bersih untuk pabrik es (liter/hari);

$\mathrm{KAB}$ : Kebutuhan air bersih untuk perkantoran (liter/hari) 


\subsection{Analisis Tarif Air Bersih}

Tarif air minum atau air bersih merupakan biaya jasa pelayanan air minum yang wajib dibayar pelanggan untuk setiap pemakaian air minum yang diberikan oleh penyelenggara. Menurut Permendagri No 23 Tahun 2006 Pedoman Teknis Dan Tata Cara Pengaturan Tarif Air Minum Pada Perusahaan Daerah Air Minum, Tarif air minum PDAM yang selanjutnya disebut tarif adalah kebijakan harga jual air minum dalam setiap meter kubik $\left(\mathrm{m}^{3}\right)$ atau satuan volume lainnya sesuai kebijakan yang ditentukan Kepala Daerah dan PDAM yang bersangkutan. Besarnya tarif air minum ditetapkan dengan keputusan Kepala Daerah atas usul Direksi setelah disetujui oleh Dewan Pengawas dengan dikonsultasikan ke Dewan Perwakilan Rakyat Daerah (DPRD). Perhitungan dan penetapan tarif air minum didasarkan pada prinsip-prinsip: keterjangkauan dan keadilan, mutu pelayanan, pemulihan biaya secara penuh (Full Cost Recovery), efisiensi pemakaian air, transparansi, akuntabilitas dan perlindungan air baku (Wayan, 2013). Keterjangkauan sebagaimana yang dimaksud dalam Permendagri 71, yakni penetapan tarif untuk standar kebutuhan pokok air minum, disesuaikan dengan kemampuan membayar pelanggan yang berpenghasilan sama dengan upah minimum Provinsi (UMP). Tarif juga tidak melampau 4\% dari pendapatan masyarakat pelanggan. Penetapan tarif untuk standar kebutuhan pokok air minum bagi masyarakat berpenghasilan rendah diberlakukan tarif setinggi-tingginya sama dengan tarif rendah. Sementara itu prinsip keadilan dicapai melalui penerapan tarif Diferensiasi dengan subsidi silang antar kelompok pelanggan dan penerapan tarif progresif dalam rangka mngupayakan penghematan penggunaan air minum.

\subsection{Analisis SWOT (Strenghts, weaknesses, opportunity, threats)}

Menurut (Fred.R, 2014), Strategi merupakan alat untuk mencapai tujuan perusahaan dalam kaitannya dengan tujuan jangka panjang, program tindak lanjut, serta prioritas alokasi sumber daya. Menurut (Ferrel, 2005), Fungsi analisa swot pada dasarnya adalah untuk memperoleh informasi terkait dengan analisis situasi kemudian mengurainya menjadi pokok persoalan internal berupa kelemahan dan kekuatan serta pokok persoalan eksternal yang meliputi ancaman dan peluang. Identifikasi kelemahan dan ancaman yang paling penting untuk diatasi secara umum pada semua komponen; Identifikasi kekuatan dan peluang yang diperkirakan cocok untuk upaya mengatasi kelemahan dan ancaman yang telah diidentifikasi lebih dahulu. Pentingnya perusahaan mengetahui faktor-faktor kunci sukses eksternal dan internal lingkungan perusahaan merupakan nilai lebih untuk daya saing perusahaan (Sari, 2010).

\section{Hasil dan Pembahasan}

\subsection{Tingkat Kebutuhan Air Bersih}

Tingkat kebutuhan air bersih PPS Lampulo dengan menghitung 3 aspek yaitu: 1) Tingkat kebutuhan air bersih untuk melaut/perbekalan, 2) Tingkat kebutuhan air bersih untuk perkantoran, dan 3) Tingkat kebutuhan air bersih untuk pabrik es. Perhitungan kebutuhan air bersih untuk melaut didasarkan pada faktor yang mempengaruhi jumlah air bersih yang dibutuhkan selama melaut seperti lama operasi penangkapan (hari/trip) dan banyak awak kapal (orang). Selain itu, dalam perhitungan kebutuhan air bersih secara teoritis dimasukkan juga nilai

Analisis Perkiraan Kebutuhan Dan Tarif Air Bersih Untuk Pelabuhan Perikanan Samudera(PPS) Lampulo Kota Banda Aceh - Putri Phara Intan, Azmeri, Eldina 
koefisien $\alpha=0,5$ yaitu koefisien cadangan air tawar di kapal dan jumlah air tawar bagi awak kapal per hari (A) yaitu sebesar 50 liter/orang/hari untuk kapal motor dan 3 liter/orang/hari untuk perahu motor tempel.

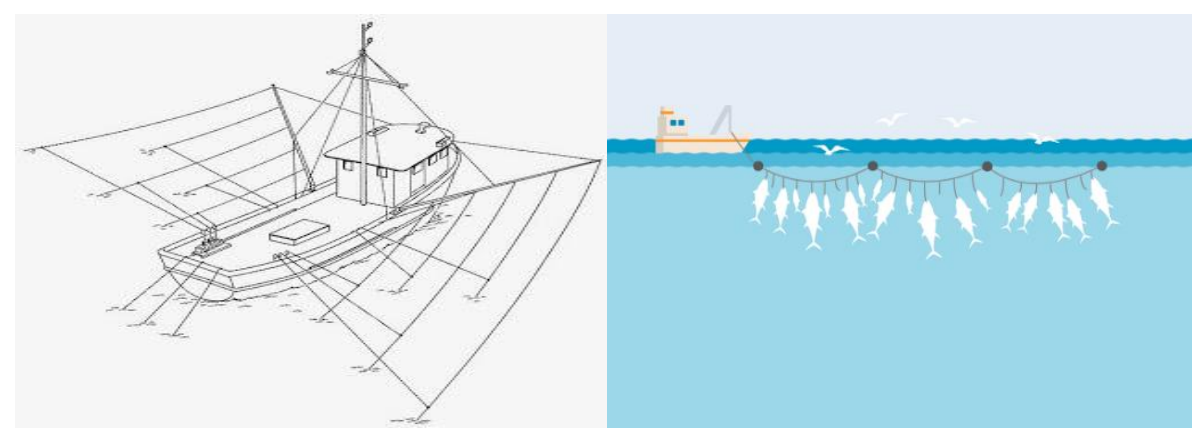

(a)

(b)

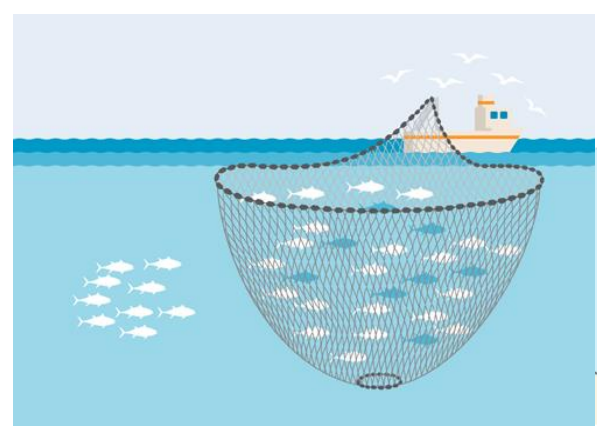

(c)

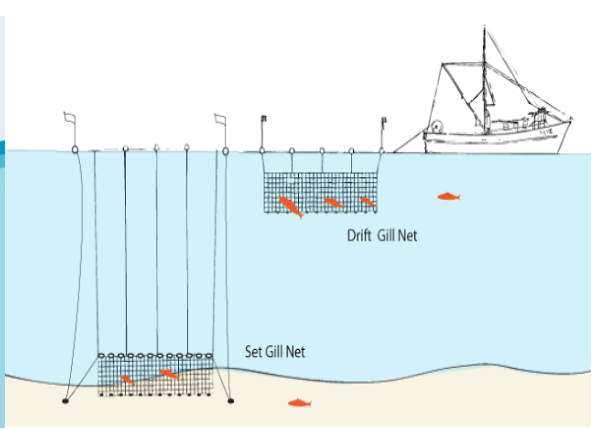

(d)

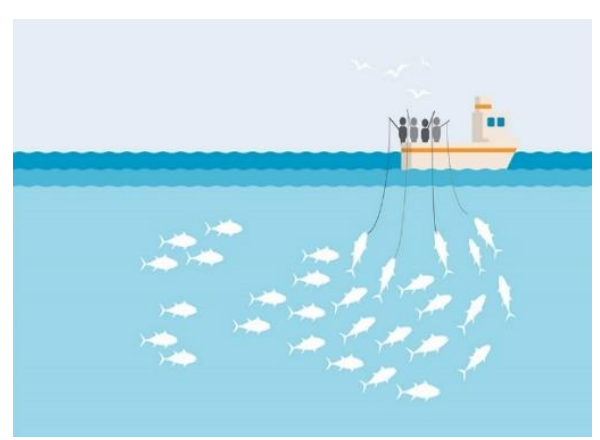

(e)

Gambar 2 Jenis kapal motor dan alat tangkap: (a) Kapal tonda; (b) Kapal longline/rawai tuna; (c) Kapal purse seine/kapal pukat cincin; (d) Kapal gillnet; dan (e) Kapal pancing ulur.

Sumber: wikipedia.org

Kapal penangkapan ikan dengan lama trip $>1$ hari pada umumnya belum dilengkapi dengan fasilitas/sarana yang layak untuk menyimpan ketersediaan air selama di kapal. Faktor yang juga turut mempengaruhi rendahnya pemanfaatan air bersih di kapal adalah untuk keperluan MCK, pencucian peralatan dan penanganan hasil tangkapan, nelayan lebih menggunakan air laut. Disamping itu, ketersediaan air bersih di kapal-kapal penangkapan lebih diprioritaskan untuk kebutuhan makan dan minum, sedangkan untuk mandi/cuci sangat terbatas atau 
sengaja dibatasi kecuali pada kapal-kapal berukuran besar seperti>100 GT. Terdapat dua perkantoran (instansi) yang berada di areal PPS Lampulo yaitu kantor syahbandar dan kantor UPTD Pelabuhan Perikanan Samudera Lampulo dengan total jumlah pegawai dan karyawan yang bekerja didalamnya 43 orang. Unit perkantoran tersebut memanfaatkan layanan air bersih dari pelabuhan untuk memenuhi berbagai keperluan sehari-hari. Berdasarkan wawancara, keperluan yang terkait air bersih tersebut meliputi untuk cuci muka, wc, air minum dan kebersihan lantai serta keperluan lainnya dengan rasio penggunaan air sebesar 1530 liter/orang/hari. Kemudian adanya 2 pabrik es yaitu: PT. TPI dan PT. Aceh Lampulo Jaya Bahari yang beroperasi untuk memenuhi perbekalan kapal yang masing-masing kapasitas produksi 24 Ton/hari dan 81 Ton/hari seperti diperlihatkan pada Tabel 2.

Tabel 2 Total tingkat kebutuhan air bersih di PPS Lampulo

\begin{tabular}{ccrc}
\hline No. & Unit Kegiatan & $\begin{array}{c}\text { Kebutuhan Aktual } \\
\text { (KA) } \\
\text { (liter/hari) }\end{array}$ & $\begin{array}{c}\text { Kebutuhan Teoritis (KT) } \\
\text { (liter/hari) }\end{array}$ \\
\hline 1 & Penangkapan & $1,350,900$ & $3,441,675$ \\
\hline 2 & Perkantoran & 645 & 460 \\
\hline 3 & Pabrik Es & 105,000 & 115,500 \\
\hline & Jumlah & $1,456,545$ & $3,557,634$ \\
\hline
\end{tabular}

Nilai kebutuhan aktual air bersih di PPS Lampulo masih jauh dibawah nilai kebutuhan teoritis. Seperti dijelaskan sebelumnya, secara umum hal ini disebabkan oleh perbedaan nilai varibel antara perhitungan kebutuhan aktual dan teoritis. Nilai variabel pada perhitungan kebutuhan aktual cenderung lebih kecil dibandingkan dengan asumsi ataupun nilai variabel pada perhitungan kebutuhan teoritis.

\subsection{Analisis Tarif Air Bersih}

Jumlah kebutuhan air bersih untuk seluruh keperluan pelabuhan serta tarif yang dikenakan untuk pembelian air bersih senilai $\mathrm{Rp} 4.200 / \mathrm{m}^{3}$ saat ini. Tarif ini seuai dengan Peraturan Walikota Banda Aceh Nomor 15 Tahun 2017 tentang Penyesuaian Kelompok Pelanggan dan Tarif Air Minum pada Perusahaan Daerah Air Minum Tirta Daroy Kota Banda Aceh untuk Kelompok III Niaga Besar per tahun 2017. Dalam Qanun Kota Banda Aceh tentang Retribusi Pelayanan Pelabuhan yang dijelaskan bahwasannya untuk jasa pelayanan air bersih fasilitas air bersih dan mobil tanki air senilai Tarif PDAM $+25 \%$ yaitu Rp. 15.000, /kendaraan, namun fakta di lapangan untuk mobil tanki dengan isian $4 \mathrm{~m}^{3}$ dibandrol harga Rp. 100.000,- /kendaraan. Tarif air bersih saat ini masih tergolong memadai sesuai dengan daya beli masyarakat/pelanggan, Namun untuk Pelabuhan Perikanan Samudera (PPS) Lampulo hanya dapat membeli air sesuai dengan yang ditetapkan, untuk mendistribusikan langsung dari jaringan perpipaan belum dapat dilaksanakan karena kekurangan air pada sumber Krueng Aceh menyebabkan PDAM Tirta Daroy tidak dapat menyalurkan langsung. Permasalahan ini telah diberikan solusi oleh Pihak PDAM Tirta Daroy kepada peneliti yang nantinya akan peneliti sampaikan kepada Pihak Pelabuhan. PDAM Tirta Daroy berharap 
agar dibangun penampungan air di kawasan PPS Lampulo agar penyaluran langsung dapat dilakukan, dari penampungan tersebut disalurkan melalui jaringan yang ada keseluruh pengguna air bersih di PPS Lampulo.

\subsection{Analisis SWOT}

Suatu strategi yang efektif dapat dirumuskan secara sistematis dengan membandingkan kondisi internal dan eksternal dari suatu sistem. Data yang diperoleh dari responden di identifikasi dan dikelompokkan menjadi faktor-faktor internal dan eksternal. Berikut Tabel 3. Matriks SWOT, di mana setiap unsur SWOT yang ada dihubungkan untuk memperoleh alternative strategi.

Tabel 3 Matriks SWOT

\begin{tabular}{|c|c|c|}
\hline Eksternal & $\begin{array}{l}\quad \text { Strenghts }(\mathrm{S}) \\
\text { - Ketersediaan ikan } \\
\text { - Penyesuaian Tarif } \\
\text { - Jumlah armada } \\
\text { - luas lahan } \\
\text { - Potensi } \\
\text { - Salah satu tempat } \\
\text { pelelangan ikan } \\
\text { - Adanya jaringan perpipaan }\end{array}$ & $\begin{array}{l}\quad \text { Weakness }(\mathrm{W}) \\
\text { - Minimnya ketersediaan air } \\
\text { bersih } \\
\text { - Fasilitas } \\
\text { - Kualitas SDM } \\
\text { - Tingkat pengaduan dan } \\
\text { pelayanan } \\
\text { - Teknologi Penangkapan } \\
\text { Ikan }\end{array}$ \\
\hline $\begin{array}{l}\quad \text { Opportunities }(\mathrm{O}) \\
\text { - Peraturan } \\
\text { - Jaringan perpipaan } \\
\text { - Sosial antar pedagang } \\
\text { - Kebutuhan air bersih } \\
\text { - Tenaga kerja \& peluang } \\
\text { usaha } \\
\text { - Dukungan masyarakat }\end{array}$ & $\begin{array}{l}\quad \underline{\text { Strategi }(\mathrm{SO})} \\
\text { - Meningkatkan produksi } \\
\text { - Membangun usaha-usaha } \\
\text { penunjang perikanan di } \\
\text { lingkungan pelabuhan } \\
\text { - Segmentasi pasar }\end{array}$ & $\begin{array}{l}\quad \text { Strategi }(\mathrm{WO}) \\
\text { - Meningkatkan kualitas } \\
\text { SDM di lingkungan PPS } \\
\text { Lampulo Kota Banda Aceh } \\
\text { - Meningkatkan } \\
\text { penggunaan teknologi } \\
\text { terkini }\end{array}$ \\
\hline $\begin{array}{l}\quad \text { Threats }(\mathrm{T}) \\
\text { - Kerusakan fasilitas di } \\
\text { Pelabuhan } \\
\text { - Ketergantungan nelayan } \\
\text { dengan tengkulak } \\
\text { - Keterbatasan modal } \\
\text { nelayan } \\
\text { - Kenaikan BBM, upah } \\
\text { minimum serta bahan } \\
\text { operasional } \\
\text { - Konflik pembayaran } \\
\text { retribusi } \\
\text { - Rendahnya peran serta } \\
\text { masyarakat dlm } \\
\text { pengelolaan }\end{array}$ & $\begin{array}{l}\quad \text { Strategi (ST) } \\
\text { - Menstabilkan dan } \\
\text { peningkatan pasokan air } \\
\text { bersih } \\
\text { - penertiban penjualan ikan } \\
\text { di PPS Lampulo } \\
\text { - Optimalisasi \& sosialisasi } \\
\text { fasilitas PPS Lampulo }\end{array}$ & $\begin{array}{l}\quad \text { Strategi }(\mathrm{WT}) \\
\text { - Bekerja sama dengan } \\
\text { pihak ketiga keterkaitan } \\
\text { pengembangan pemasokan } \\
\text { kebutuhan fasilias PPS } \\
\text { Lampulo } \\
\text { - Meningkatkan koordinasi } \\
\text { yang baik dengan } \\
\text { masyarakat }\end{array}$ \\
\hline
\end{tabular}

Analisis Perkiraan Kebutuhan Dan Tarif Air Bersih Untuk Pelabuhan Perikanan Samudera(PPS) Lampulo Kota Banda Aceh - Putri Phara Intan, Azmeri, Eldina 
Berdasarkan Tabel 3 Matriks SWOT, untuk Strategi yang sedang dan akan dijalankan sesuai dengan RENSTRA PPS Lampulo Kementrian Lautan dan Perikanan yaitu adanya Stasiun Karantina Ikan Pengendalian Mutu dan Keamanan Hasil Perikanan (SKIPM) Aceh akan segera membuka kantor wilayah kerjanya di Pelabuhan Perikanan Samudera (PPS) Lampulo, Banda Aceh. Kantor wilayah kerja ini, nantinya akan dimanfaatkan untuk meningkatkan pelayanan kepada para pelaku usaha di kawasan PPS Lampulo tersebut. Dengan dibangunnya kantor wilker karantina ikan di kawasan PPS Lampulo ini, diharapkan akan berdampak pada ketelusuran produk hasil perikanan, mulai dari kapal penangkap dan alat tangkap yang digunakan hingga yang lainnya juga adanya kerja sama dengan pihak ketiga agar memenuhi kebutuhan air bersih, solar dan lainnya untuk jangka waktu yang cukup lama. karena jika upaya pembangunan tidak didukung oleh pengelolaan yang baik dan pertumbuahan armada serta hasil tangkapan dalam jumlah banyak serta pelayanan yang baik bagi kapal-kapal besar baik kapal lokal (Aceh) atau kapal luar daerah maka ini bisa menjadi ancaman bagi PPS Lampulo sendiri dan menjadikan upaya pengembangan menjadi sia-sia dan tidak menguntungkan sama sekali.

\section{Kesimpulan dan Saran \\ 4.1 Kesimpulan}

Tingkat kebutuhan air bersih untuk seluruh keperluan PPS Lampulo secara teoritis sebesar $\mathrm{Rp}$ 3,557,634 liter/hari sedangkan secara aktual sebesar $\mathrm{Rp}$ 1,456,545 liter/hari. Nilai kebutuhan aktual air bersih masih jauh dibawah nilai kebutuhan teoritis, secara umum hal ini disebabkan oleh perbedaan nilai varibel antara perhitungan kebutuhan aktual dan teoritis. Nilai variabel pada perhitungan kebutuhan aktual cenderung lebih kecil dibandingkan dengan asumsi ataupun nilai variabel pada perhitungan kebutuhan teoritis. Tarif air bersih saat ini masih tergolong memadai sesuai dengan daya beli masyarakat/pelanggan, Namun untuk Pelabuhan Perikanan Samudera (PPS) Lampulo hanya dapat membeli air sesuai dengan Peraturan Walikota Banda Aceh Nomor 15 Tahun 2017 tentang Penyesuaian Kelompok Pelanggan dan Tarif Air Minum pada Perusahaan Daerah Air Minum Tirta Daroy Kota Banda Aceh untuk Kelompok III Niaga Besar per tahun 2017 sebesar Rp. 4.200/m². Implementasi strategi pengelolaan air bersih dan sarana pelabuhan perikanan adalah strategi W-T (Weakness - Treats), dengan prioritas utama meminta dukungan pemerintah terkait kapasitas dan kapabilitasnya dalam pengelolaan air bersih dan sarana prasaranan PPS Lampulo.

\subsection{Saran}

Perlu ditata kembali manajemen pengelolaan pelabuhan perikanan, pihak PPS perlu menambah bak penampung untuk PDAM mengalirkan air sebanyak 5 liter/detik setiap harinya. Juga perlu penambahan jaringan perpipaan untuk mengalirkan air dari bak penampung ke seluruh unit yang membutuhan air bersih. Serta pengembangan pelabuhan dimasa yang akan datang perlu perlu membuka kran investor supaya menanamkan modalnya, serta perlu perhatian pemerintah pusat dan daerah baik material dan non material.

Analisis Perkiraan Kebutuhan Dan Tarif Air Bersih Untuk Pelabuhan Perikanan Samudera(PPS) Lampulo Kota Banda Aceh - Putri Phara Intan, Azmeri, Eldina 


\section{Daftar Kepustakaan}

Bambang, M. (2003) 'Pelabuhan Perikanan', Fakultas Perikanan dan Ilmu Kelautan, Institut Pertanian Bogor.

Dwijosaputro (1981) 'Dasar-Dasar Mikrobiologi', Djambatan, Jakarta.

Ferrel, O. . and H. (2005) 'Marketing Strategi', South West; Thomson Corporation.

Fred.R, D. (2014) 'Analisa Swot Teknik Membedah Kasus Bisnis', Jakarta: Gramedia Pustaka Utama.

Guswanto, B. (2012) 'Analisis Indeks Kinerja Pengelola dan Indeks Kepuasan Pengguna Di Pelabuhan Perikanan Samudera Nizam Zachman Jakarta', Perikanan dan Kelautan, 66(4), pp. 37-39.

Lubis, E. (2000) Pengantar Pelabuhan Perikanan. Bahan Kuliah Pelabuhan Perikanan. Bogor: Laboratorium Kelautan, Departemen Pemanfaatan Sumberdaya Perikanan, Institut Pertanian Bogor.

Lubis, E. (2002) 'Pengantar Pelabuhan Perikanan', Fakultas Perikanan dan Ilmu Kelautan, Institut Pertanian Bogor. Bogor: Fakultas Perikanan dan Ilmu Kelautan, Institut Pertanian Bogor,.

Pane, A. (2011) 'Bahan Kuliah Teknologi Industri Pelabuhan Perikanan', Mayor Teknologi Penangkapan Ikan. Program Pascasarjana IPB. Bogor.

Rahmawati, W. (2014) 'Pengembangan Pelabuhan Perikanan Dalam Rencana Penyerapan Tenaga Kerja Masyarakat Pesisir (Studi Pada Pelabuhan Perikanan Nusantara Brondong Kabupaten Lamongan))', Jurnal Administrasi Publik Mahasiswa Universitas Brawijaya, 2(2), pp. 367-373.

Sari, Y. P. (2010) 'Berdaya Saing ( Studi pada Dealer Honda Tunggul Sakti di Semarang )', p. 75.

Wayan (2013) 'Analisis Perubahan Penggunaan Air Minum Sebelum dan Setelah Kenaikan Tarif PDAM Kota Denpasar', Jurusan Teknik Sipil, Fakultas Teknik Universitas Udayana, Denpasar, 2(2), pp. 1-6.

Copyright (c) putri phara intan

Analisis Perkiraan Kebutuhan Dan Tarif Air Bersih Untuk Pelabuhan Perikanan Samudera(PPS) Lampulo Kota Banda Aceh - Putri Phara Intan, Azmeri, Eldina 